Composites: Part A 63 (2014) 68-75

http://dx.doi.org/10.1016/j.compositesa.2014.04.005

(c) 2014.

This manuscript version is made available under the CC-BY-NCND 4.0 license http://creativecommons.org/licenses/by-nc-nd/4.0/

\title{
Structural, physical and damping properties of melt-spun Ni-Mn-Ga wire-epoxy composites
}

S. Glock ${ }^{\mathrm{a}}$, X.X. Zhang ${ }^{\mathrm{b}}$, N.J. Kucza ${ }^{\mathrm{c}}$, P. Müllner ${ }^{\mathrm{c}}$ and V. Michaud ${ }^{\mathrm{a},}$

${ }^{a}$ Laboratoire de Technologie des Composites et Polymères, Ecole Polytechnique Fédérale de Lausanne, Lausanne, 1015, Switzerland

${ }^{b}$ School of Materials Science and Engineering, Harbin Institute of Technology, Harbin, 150001, China

${ }^{c}$ Department of Materials Science and Engineering, Boise State University, Boise, Idaho, 83725, USA

\begin{abstract}
Ni-Mn-Ga is a ferromagnetic shape memory alloy that exhibits large, magnetic-fieldand stress-induced strains via energy dissipating twinning when processed into single crystals. Grain boundaries suppress twinning and render polycrystalline Ni-Mn-Ga brittle. $\mathrm{Ni}-\mathrm{Mn}-\mathrm{Ga} /$ polymer composites overcome the drawbacks of polycrystals and could thus provide a less expensive and easier to handle alternative to Ni-Mn-Ga single crystals for damping applications. Ni-Mn-Ga wires were produced by melt-spinning and were polycrystalline in the as-spun state. Annealed wires were ferromagnetic at room temperature with non-modulated martensite and a bamboo microstructure. The annealed wires displayed a hysteretic stress-strain behavior typical for twinning. Ni-Mn-Ga wire-
\end{abstract}

Corresponding author. Tel: +41216934923. E-mail address: veronique.michaud@epfl.ch. 
epoxy matrix composites were fabricated with as-spun and annealed wires. The damping behavior of annealed Ni-Mn-Ga wire-epoxy matrix composites was higher than that of asspun Ni-Mn-Ga wire-epoxy matrix composites and of pure epoxy.

Keywords: A: Polymer-matrix composites (PMCs), A: Fibers, B: Internal friction/Damping, B: Mechanical properties.

\section{Introduction}

Ni-Mn-Ga is a ferromagnetic shape memory alloy (FSMA). Its magnetic-fieldinduced strain (MFIS), caused by twin boundary motion, was first reported by Ullakko et al. [1] in 1996. Currently, Ni-Mn-Ga is of great interest due to its large MFIS of up to $10 \%$ [2] at an actuation frequency of up to $2 \mathrm{kHz}$ [3]. Beside magnetic-field-induced twinning, twin boundary motion can be induced by mechanical stresses. The maximum strain $\varepsilon$ achieved by applying a mechanical stress to a Ni-Mn-Ga single crystal depends on the lattice parameters $a$ and $c$ as $\varepsilon=1-c / a$. Thus, 10M pseudo-tetragonal, 14M pseudoorthorhombic and NM tetragonal martensite exhibit a maximum twinning strain of $6 \%$, $10 \%$ and $20 \%$, respectively [4].

Polycrystalline Ni-Mn-Ga is brittle. Furthermore, grain boundaries hinder twinning, increase the twinning stress and suppress MFIS. Single crystals of Ni-Mn-Ga, however, are expensive to produce. Here, we propose to overcome limitations of polycrystals with composites of Ni-Mn-Ga fibers in a polymer matrix. In wires and foams with grains as large as the element diameter (bamboo structure), twin boundaries span across entire grains and are mobile, resulting in large MFIS [5-7]. Such elements can then be embedded in a polymer matrix to form a solid structure. Ni-Mn-Ga powder composites with single- 
crystalline FSMA particles and broken up fibers were reported recently [8-12], but very little is known for composites with wires having a length to diameter ratio greater than 100 .

For application requiring isothermal high strain and high frequency actuation, the twinning stress has to be less than the magneto stress (which is about $3 \mathrm{MPa}$ [13] for Ni$\mathrm{Mn}-\mathrm{Ga})$ to ensure magnetic-field-induced twin boundary motion [14]. For applications requiring damping however, the twinning stress needs to be high to guarantee that the dissipative twin boundary motion induced by applying a mechanical stress results in a high dissipation rate. Due to the low twinning stresses of $10 \mathrm{M}$ and $14 \mathrm{M}$ martensite (as low as $0.1 \mathrm{MPa}[14,15])$ these martensites can be used as actuator. In NM martensite, twinning occurs typically at much higher stresses of 10-20 MPa [4]. This prevents NM martensite from being used as actuator but it is promising for damping applications.

In this work, as-spun and annealed melt-spun $\mathrm{Ni}-\mathrm{Mn}-\mathrm{Ga}$ wires were thus characterized for their transformation temperature and crystal structure as well as for their mechanical and magnetic behavior. Furthermore, the thermal characteristics of the epoxy used as matrix material were analyzed. Finally, composites with Ni-Mn-Ga wires and epoxy matrix were processed, and their thermal and damping behavior was studied with differential scanning calorimetry and dynamic mechanical analysis experiments, respectively.

\section{Experimental}

The Ni-Mn-Ga wires were prepared from a $\mathrm{Ni}_{50.3 \pm 0.2} \mathrm{Mn}_{28.8 \pm 0.7} \mathrm{Ga}_{20.9 \pm 0.5}$ ingot by meltspinning, as described in Ref. [16]. The wires had a diameter of 30 to $90 \mu \mathrm{m}$ and a length of up to $4 \mathrm{~cm}$. About half of the more than one hundred wires were annealed at $1000^{\circ} \mathrm{C}$ for 
$3 \mathrm{~h}$ in a sealed, evacuated and argon backfilled quartz tube, containing $\mathrm{Ti}$ and $\mathrm{Mn}$, to stimulate grain growth. Ti served as oxygen getter. Mn was added to the quartz tube to create a Mn atmosphere and prevent loss of Mn via evaporation. Microstructure and composition of the wires were characterized with a FEI XLF30-FEG scanning electron microscope equipped with an energy dispersive X-ray spectroscopy probe (EDS). The transformation temperatures were detected by performing differential scanning calorimetry tests using a DSC Q100 from TA Instruments with a heating/cooling rate of $5{ }^{\circ} \mathrm{C} / \mathrm{min}$. To determine the Curie temperature, the magnetization was measured as a function of temperature in a magnetic field of $25 \mathrm{mT}$ using a MicroSense Model 10 Vibrating Sample Magnetometer (VSM) with a heating rate of $6{ }^{\circ} \mathrm{C} / \mathrm{min}$ and a cooling rate of $4{ }^{\circ} \mathrm{C} / \mathrm{min}$. The crystal structure was determined with x-ray diffraction experiments using a Bruker D8 Discover diffractometer with $\mathrm{Cu} \mathrm{K} \alpha$ radiation.

To determine the mechanical properties of the melt-spun wires at different gauge lengths varying from 1.5 to $13 \mathrm{~mm}$ for the as-spun and from 1.5 to $8 \mathrm{~mm}$ for the annealed wires, tensile tests of the single wires were performed at room temperature. Each wire was glued with cyanoacrylate-glue on the clamps of a UTS tensile testing machine equipped with a home-made $5 \mathrm{~N}$ load cell. Besides loading the wires until fracture, loading-unloading cycles up to a maximum strain of about $0.7 \%$ and $2 \%$, respectively, was performed for the as-spun and annealed wires with a gauge length of $3 \mathrm{~mm}$. In all loading cases, the test speed was set to $0.005 \mathrm{~mm} / \mathrm{s}$.

As matrix material, the epoxy system Araldite LY 3297/Aradur 3298 (with a mix ratio of 100:40 by weight) from Huntsman, USA was chosen. This epoxy system is a commercially available, standard epoxy with a Young's modulus (E-modulus) of about 
$3 \mathrm{GPa}$ at room temperature. Curing schedule was for $9 \mathrm{~h}$ at $80^{\circ} \mathrm{C}$. Resulting glass transition temperature was measured with a differential scanning calorimeter (DSC Q100 from TA Instruments) with a heating/cooling rate of $5{ }^{\circ} \mathrm{C} / \mathrm{min}$.

Composites were produced with vacuum infusion. The wires were placed and aligned by hand, as illustrated in Fig. 1, in a mold composed of a metallic bottom plate, silicone walls and a movable metallic cover bar that fits in the gap of about $3 \mathrm{~mm}$ width of the silicon walls. The resin was mixed, degassed for $30 \mathrm{~min}$ and then infused at room temperature to fill the mold with minimal movement of the wires and formation of pores. The wire volume fraction of the composites was determined by the packing of the wires under the pressure of the metallic cover bar induced by the vacuum bag and resulted in about 20 to 25 vol.\%. As a reference, pure epoxy was also cast in a silicon mold, cured like the composite specimens at $80^{\circ} \mathrm{C}$ for $9 \mathrm{~h}$ and ground to obtain about the same height as the composite specimens. The final specimen heights were $0.50 \mathrm{~mm}$ for the pure epoxy samples ( 4 specimens), about $0.45 \mathrm{~mm}$ for the as-spun Ni-Mn-Ga wire-epoxy matrix composites ( 3 specimens) and about $0.40 \mathrm{~mm}$ for the annealed Ni-Mn-Ga wire-epoxy matrix composites ( 4 specimens). To determine the morphology of the wire composites, surface and cross-section were observed under an optical microscope. Damping tests were conducted on a TA Instruments DMA Q800, USA, in a temperature range from 0 to $120^{\circ} \mathrm{C}$ with a heating rate of $5{ }^{\circ} \mathrm{C} / \mathrm{min}$ using the single cantilever mode with a maximum strain amplitude of $0.5 \%$ and a frequency of $1 \mathrm{~Hz}$. The gauge length was $17.56 \mathrm{~mm}$ for all samples. In order to better interpret the results of the damping tests, DSC tests were performed in addition on the composites using the same heating/cooling rate as for the DMA tests. 


\section{Results}

\subsection{Characterization of the melt-spun wires}

Fig. 2 shows SEM micrographs of the as-spun $(a, b)$ and annealed (c, d) Ni-Mn-Ga wires. All wires exhibited an irregular diameter and a semi-circular cross section. The grains of the as-spun wires were dendritic-like. The annealed wires, in contrast, had a bamboo- or near-bamboo microstructure with twinned grains as large as the wire diameter. The twins of the different grains seem to be randomly oriented.

Table 1 summarizes the composition of the as-spun and annealed wires measured with EDS on the wire surface and on the fractured cross section. The concentrations were averaged over six measurements (two per wire) in case of the surface data and four measurements (one per wire) in case of the cross section data and are given with the standard deviations. Within the experimental error, the composition did not change during annealing.

The DSC curves are shown in Fig. 3. The corresponding transformation temperatures as well as the Curie temperatures obtained from the VSM measurements are summarized in Table 2. Annealing of the wires resulted in a sharper martensitic transformation with significantly larger enthalpy of reaction. Furthermore, the austenite start temperature shifted from $82^{\circ} \mathrm{C}$ to $97^{\circ} \mathrm{C}$ and the Curie temperature from $93^{\circ} \mathrm{C}$ to $101^{\circ} \mathrm{C}$.

Fig. 4 presents the XRD patterns of as-spun and annealed wires. Both types of wires exhibited a martensite structure at room temperature however with a different modulation. While the as-spun wires had the $14 \mathrm{M}$ structure with $a=6.17 \AA, b=5.80 \AA$ and $c=5.47 \AA$, the annealed wires had the NM structure with $a=5.46 \AA$ and $c=6.54 \AA$. 
Typical stress-strain curves of an as-spun and annealed wire are shown in Fig. 5. While the as-spun wire failed in a brittle mode, the annealed wires exhibited a saw-tooth stress-strain behavior.

The mechanical properties of the as-spun and annealed wires, determined from the stress-strain curves, are presented in Fig. 6. The modulus, in particular, was calculated from the slope of the linear deformation between $0.05 \%$ and $0.25 \%$. For both types, properties varied strongly from sample to sample. The as-spun wires fractured all in a brittle mode with fracture strengths ranging from 107 to $465 \mathrm{MPa}$, an E-modulus between 7.4 and 60.6 GPa and a strain at failure of 0.8 to $6.1 \%$. Annealed wires exhibited apparent moduli ranging from 2.0 to $14.1 \mathrm{GPa}$ and deformed with pronounced stress serrations above a stress ranging between 10 and $30 \mathrm{MPa}$ to a strain of 0.3 to $7.0 \%$ and a strength of 19 to $90 \mathrm{MPa}$.

Loading-unloading cycles are shown in Fig. 7. For small strains, Fig. 7 (a), the asspun wire deformed in a linear-elastic mode whereas the annealed wire displayed a hysteresis. The as-spun wires exhibited slight plastic deformation when loaded close to failure, Fig. 7 (b), but their plastic deformation was minimal in comparison to the plastic strain of the annealed wires.

\subsection{Thermal properties of the matrix material}

The DSC curves of the cured epoxy system Araldite LY 3297/Aradur 3298 are shown in Fig. 8. In the first heating curve, a small endothermic peak at about $63{ }^{\circ} \mathrm{C}$ overlapped with the glass transition but no exothermal peak could be observed. The glass transition temperature $\left(T_{g}\right)$, obtained from the second heating/cooling cycle was $90{ }^{\circ} \mathrm{C}$ during heating 
and $88{ }^{\circ} \mathrm{C}$ during cooling. The width of the glass transition (temperature difference of the two onset points) was $18{ }^{\circ} \mathrm{C}$ and $25^{\circ} \mathrm{C}$ for heating and cooling, respectively.

\subsection{Ni-Mn-Ga wire-epoxy matrix composites}

\subsubsection{Characterization}

Fig. 9 presents micrographs of the surface (a) and cross section (b) of a Ni-Mn-Ga wire-epoxy matrix composite. Most of the wires showed a preferred orientation along or close to the sample axis. The distribution of the wires over the sample width and thickness was not perfectly homogeneous but no deposition of the wires on the bottom of the sample could be observed. Furthermore, no pores were visible.

In Fig. 10, the DSC curves of one as-spun and one annealed Ni-Mn-Ga wire-epoxy matrix composite, respectively, are presented. The transformation temperatures and the increase of the enthalpy of reaction induced by the annealing of the Ni-Mn-Ga wires were the same as for the non-embedded wires. In the first heating curve, another small endothermic peak like in the DSC curve of the epoxy could be observed for both composite types. For the other composite samples, the thermal behavior was identical to that of the examples shown.

\subsubsection{Damping measurements}

Fig. 11 illustrates the storage modulus and loss ratio $(\tan \delta)$ dependency on temperature for a heating rate of $5{ }^{\circ} \mathrm{C} / \mathrm{min}$ for one of each sample types: epoxy, as-spun $\mathrm{Ni}$ Mn-Ga wire-epoxy matrix composite and annealed Ni-Mn-Ga wire-epoxy matrix composite as well as the scatter of the values for the different samples, shown only as points at room temperature for the sake of clarity. Up to about $70{ }^{\circ} \mathrm{C}$ the loss ratio was 
almost constant and the storage modulus decreased slowly for all samples. Above $70{ }^{\circ} \mathrm{C}$, the behavior was more complex. All epoxy samples exhibited a significant decrease of the storage modulus and a significant increase of the loss ratio at about $90{ }^{\circ} \mathrm{C}$ resulting in a peak with a maximum about $102{ }^{\circ} \mathrm{C}$. For the two types of composite samples, two overlapping $\tan \delta$ peaks could be observed. The peak maxima varied from sample to sample and were between about $80^{\circ} \mathrm{C}$ and $115^{\circ} \mathrm{C}$ for the first, smaller peak. The second peak was above about $115^{\circ} \mathrm{C}$ and could even not be detected in the measurement range of up to $120^{\circ} \mathrm{C}$ for all samples. Furthermore, the extent of the small peak shoulder was different for each sample, but on average larger for the annealed wire composites in comparison to the as-spun wire composites.

Up to about $70{ }^{\circ} \mathrm{C}$, the storage modulus for the as-spun Ni-Mn-Ga wire-epoxy matrix composite ( $6.3 \pm 0.4 \mathrm{GPa}$ at room temperature) was higher than that of the annealed Ni-MnGa wire-epoxy matrix composite $(5.1 \pm 0.3 \mathrm{GPa}$ at room temperature), which was higher than that of the pure epoxy ( $3.4 \pm 0.2 \mathrm{GPa}$ at room temperature). For the loss ratio, both composite types exhibited larger values than the epoxy. The composite with annealed NiMn-Ga wires embedded in epoxy had a larger loss ratio than the as-spun Ni-Mn-Ga wireepoxy matrix composite.

\section{Discussion}

\subsection{Characterization of the melt-spun wires}

The structure of the melt-spun wires is characterized by an irregular diameter and a semi-circular cross section. The as-spun wires exhibit dendritic-like grains. Both, structure and microstructure of the as-spun wires, correspond well to that expected from the rapid 
solidification, typical for melt-spinning [16]. The chosen annealing conditions allow the formation of the desired bamboo or near-bamboo microstructure. According to the random orientation of the twins, the wires do not seem to have a crystallographic texture. This is coincident with observations of Scheerbaum et al. [6] made for Ni-Mn-Ga wires produced with a similar technique.

The wire drawing process causes a small manganese loss of less than 0.2 at.\%. The manganese loss during annealing is within experimental error, i.e. not possible to quantify.

The annealed wires show a sharper transformation with significantly larger enthalpy of transformation than the as-spun wires. This is attributed to several causes: The presence of internal stresses and obstacles such as structural inhomogeneity and grain boundaries could partly inhibit the martensitic transformation in the as-spun wires, leaving some remaining austenitic phase. This, however, cannot be confirmed by observation of the XRD results, since the peaks cannot be resolved. Nonetheless, internal stresses are often reported to cause a broadening of the enthalpy peak. Another reason for the increased enthalpy of transformation is the change from $14 \mathrm{M}$ to NM martensite after heat treatment. As observed by Jiang et al. [17], the enthalpy of transformation from $14 \mathrm{M}$ martensite to austenite is smaller than the transformation enthalpy of NM martensite to austenite even for the same composition.

Annealing furthermore increased the martensitic transformation temperature $\left(T_{m}=\left(A_{s}+M_{f}\right) / 2\right)$ by $19^{\circ} \mathrm{C}$ and the Curie temperature $\left(T_{c}\right)$ by $8{ }^{\circ} \mathrm{C}$. Such a temperature increase of $T_{m}$ and $T_{c}$ was reported in the literature for the annealing of melt-spun Ni-MnGa ribbons $[8,18]$ and for the structural inconformity of Ni-Mn-Ga in powder and bulk state [17]. Scheerbaum et al. [8] suggested several reasons for the temperature shift during 
annealing: As $T_{m}$ and $T_{c}$ are strongly dependent on the composition [19, 20], manganese evaporation during annealing might shift $T_{m}$ and $T_{c}$. Here, however, the manganese loss is within experimental errors. Also, the differences in grain size between the as-spun and annealed wires could lead to a stronger undercooling of the martensitic transformation for the as-spun wires. Finally, another explanation given in Ref. [8] for the increase of $T_{m}$ might be inhomogeneities, precipitates or local composition differences around defects in the as-spun wires that disappear due to diffusion during the heat treatment. Chemical ordering during annealing could also explain the increase of $T_{c}$. In addition, since in our case annealing comes along with a structural change from 14M to NM martensite, the lower free energy of NM compared to $14 \mathrm{M}$ is an additional reason for the increase of $T_{m}$. NM is more stable than $14 \mathrm{M}$ resulting in a larger overheating of the reverse martensitic transformation [17].

The change of the martensitic crystal structure during heat treatment could be attributed to a change in the composition $[19,20]$, i.e. manganese evaporation during annealing, which is not the case in our work. Another cause could be the differences in grain size and internal stresses, as indicated by Pons et al. [21] for Ni-Mn-Ga bulk and melt-spun ribbons of the same composition. They detected a NM structure for the Ni-Mn$\mathrm{Ga}$ in the bulk state and a $14 \mathrm{M}$ structure for the ribbons. They attributed this difference to the mechanisms that take place to obtain the NM or the $14 \mathrm{M}$ structure, respectively. In the notion of adaptive martensite, twinning in NM martensite is considered as macroscopic twinning. In contrast, 14M martensite is considered to be the result of periodic microtwinning [21]. A $14 \mathrm{M}$ structure is obtained for the ribbons because the small grain size and internal stresses in the melt-spun ribbons do not allow macroscopic twinning. A 
similar transition from NM to $14 \mathrm{M}$ martensite after severe plastic deformation leading to ultrafine grains was observed and also attributed to adaptive martensite by Waitz et al. [22]. The same phenomenon could occur in the as-spun wires that have small grains and internal stresses induced by the rapid solidification. The annealing of the wires, however, results in grains as large as the wire diameter and less internal stresses so that macroscopic twinning becomes possible rendering the NM equilibrium structure of the martensite.

As-spun and annealed wires respond differently to mechanical loading. The annealed wires, exhibiting a bamboo-microstructure, show a serrated stress-strain behavior and break along the grain boundaries, which are the weakest links of the wire. This behavior indicates an individual response of the different grains with several deformation modes possible. One mode is related to stress-induced intermartensitic transformations as observed for example by Segui et al. [23]. However, it is unlikely that this is the deformation mechanism of the annealed NM wires because the NM martensite is more stable than the layered $10 \mathrm{M}$ and 14M structures. Deformation twinning, as observed amongst others by Sozinov et al. [4] and Likhachev et al. [24], is another possible deformation mode. The twinning stress of 10$50 \mathrm{MPa}$ corresponds to values reported for NM martensite (e.g. 12-20 MPa in [4]) and indicates that deformation of the annealed wires most likely occurs by twinning. In as-spun wires, which exhibit small dendritic-like grains, twinning is hindered by the surrounding grains resulting in linear-elastic deformation and brittle failure. The different deformation modes of as-spun and annealed wires are also responsible for the differences in the strain at failure and wire strength. Stress induced twinning allows the annealed wires to deform more extensively and results in a higher strain at failure. Fracture along the grain boundaries, on the other hand, causes a reduction of the wire strength. The as-spun wire 
exhibit the same modulus during loading and unloading whereas for the annealed wire the apparent modulus during loading is smaller than that during unloading. This indicates that the as-spun wires deform elastically and the modulus obtained from the single wire tensile tests corresponds to the Young's modulus. The measured modulus of the annealed wires, however, is due to the anelastic strains caused by twinning resulting in an apparent modulus that is smaller than the Young's modulus. Thus, the Young's modulus of the annealed wires cannot be measured using this method.

The fracture stress of brittle materials typically follows the Weibull statistics [25]. Such a behavior is also found here. The data for all gauge lengths could be fitted with a two-parameter Weibull distribution, $P(\sigma)=1-\exp \left[-\frac{l}{l_{0}}\left(\frac{\sigma}{\beta}\right)^{\alpha}\right]$, where $\alpha$ and $\beta$ are shape and scale parameters, respectively, of the Weibull distribution, $l$ designates the wire gauge length and $l_{0}$ the reference length. The shape parameter is 5 for the as-spun and 4 for the annealed wires and the scale parameter is $498 \mathrm{MPa}$ and $77 \mathrm{MPa}$, respectively [26].

\subsection{Thermal properties of the matrix material}

The absence of an exothermic peak during the first heating cycle indicates that the epoxy is fully cured. The endothermic peak in the first heating curve is attributed to physical aging of the cured epoxy [27]. Since the samples were stored at room temperature, which is much below $T_{g}$, the aging peak is very small, below the glass transition temperature. It is important to note that the glass transition of the matrix takes place in the same temperature range as the martensitic transformation of both the as-spun and annealed Ni-Mn-Ga wires. 


\subsection{Ni-Mn-Ga wire-epoxy matrix composites}

\subsubsection{Characterization}

The distribution of the Ni-Mn-Ga wires in the epoxy is not perfectly homogeneous, but a good portion of the wires is aligned with or close to the sample axis. This morphology originates from the manual placing and alignment of the wires in the mold. A deposition of the wires on the bottom of the sample is prevented by the steric hindrance of the wires. The composite is fully infiltrated with no porosity, indicating that vacuum infusion is an adequate technique to produce Ni-Mn-Ga wire-epoxy matrix composites.

The observed thermal behavior of the Ni-Mn-Ga wire-epoxy matrix composites is the superposition of the thermal behavior of the Ni-Mn-Ga wires and of the epoxy. Both temperatures of the martensite/austenite transformation and temperature of the endothermic aging peak are consistent with the temperatures observed for the wires and epoxy, respectively. Also the increase of the enthalpy of transformation is observed for the composite samples. Only the glass transition of the epoxy can not be observed in the DSC curves of the composites due to the low epoxy mass fraction (27-33wt.\%) and the overlapping with the large peak of the martensite/austenite transformation. Thus, the chosen epoxy does not affect or hinder the martensite/austenite transformation.

\subsubsection{Damping measurements}

The observed order of the storage modulus (as-spun Ni-Mn-Ga wire-epoxy matrix composite followed by annealed Ni-Mn-Ga wire-epoxy matrix composite and epoxy) corresponds qualitatively to the reinforcement effect of the $\mathrm{Ni}-\mathrm{Mn}-\mathrm{Ga}$ wires and the apparently higher modulus of the as-spun wires compared to the annealed ones, Fig. 8 (e, f). 
Using a simple rule of mixture approach and assuming all wires are aligned, a value for the modulus of the wires at room temperature can be estimated. This leads to $17.7 \mathrm{GPa}$ for the as-spun wires and $11.8 \mathrm{GPa}$ for the annealed wires. For the as-spun wires, the value is lower than the directly measured one, $28.3 \pm 13.2 \mathrm{GPa}$. This could be attributed to misalignment of the wires, to the fact that the wires are shorter than the sample and possibly to non perfect adhesion between wire and matrix. On the other hand, the higher value found for the annealed wires $(5.3 \pm 3.2 \mathrm{GPa}$ was obtained for single wire tensile test) confirms the underestimation of the modulus due to anelastic effects, which are less marked in the oscillatory mode at small amplitude.

Regarding the almost constant loss ratios up to about $70^{\circ} \mathrm{C}$, the annealed Ni-Mn-Gaepoxy matrix composite shows the highest values followed by the as-spun Ni-Mn-Gaepoxy matrix composite and the epoxy. This order is consistent with the dissipative effect of the wire-matrix-interface as reported in composites with other fibrous reinforcements [28] and the dissipative effect of the twin boundary motion. While both types of composites have imperfect wire-matrix interfaces, twin boundary motion takes place only in the annealed wires. Similar results were found among others by Feuchtwanger et al. [9, 29] and Lahelin et al. [12] for Ni-Mn-Ga powder- polymer matrix composites. Unfortunately, the stiffness of the samples was close to the minimum limit for the single cantilever mode of the DMA, potentially leading to an underestimation of the loss ratio.

Above $70{ }^{\circ} \mathrm{C}$, the behavior is more complex. The epoxy shows a significant increase of the loss ratio and a significant decrease of the storage modulus, respectively, at about $90{ }^{\circ} \mathrm{C}$. This is, according to DSC measurements on the epoxy, associated with the glass transition temperature, $T_{g}$, of the epoxy. For both types of composites, the glass transition 
of the epoxy as well as the martensitic phase transformation of the Ni-Mn-Ga wires take place and cause a $\tan \delta$ peak at their transformation temperature as observed by Sun at al. [10] for Ni-Mn-Ga powder-epoxy matrix composites. Since for the composites tested here both transition temperatures are overlapping, as discussed above, the $\tan \delta$ peaks are to a greater or lesser extent pronounced double peaks, with the maximum peak temperature varying between samples. Note that transient damping effects take place during the transformation, and have been reported even in the martensitic state. These are strongly related to the heating and cooling rates, as observed for thermally activated shape memory alloys [30], making the damping results dependent on the thermal history of the test, in particular during the transformation. Since the influence of transient damping has not been quantified for Ni-Mn-Ga wires and their composites, the comparison of results at this stage is only valid for similar heating rates.

\section{Conclusions}

Annealing melt-spun Ni-Mn-Ga wires at $1000{ }^{\circ} \mathrm{C}$ induced grain growth and resulted in a bamboo microstructure. Annealing shifted the martensitic transformation and Curie temperature to higher temperatures and changed the crystal structure from $14 \mathrm{M}$ to the more stable NM martensitic structure. The bamboo microstructure reduced strength and increased strain to failure and introduced a hysteretic stress-strain behavior caused by twinning. Composites using these wires were successfully produced by vacuum infusion of an epoxy resin, and cured to reach a $T_{g}$ of about $90^{\circ} \mathrm{C}$. Regarding their damping behavior, the highest loss ratio was found for the annealed Ni-Mn-Ga wire-epoxy matrix composite which could be related to the dissipative motion of twin boundaries and the dissipative 
effect of the wire/matrix interface. As a result, Ni-Mn-Ga wire-epoxy matrix composites could provide an alternative to single crystal $\mathrm{Ni}-\mathrm{Mn}-\mathrm{Ga}$ that is less expensive and easier to handle for damping applications.

\section{Acknowledgement}

This work is supported by the Swiss National Science Foundation under the National Research Programme NRP $62 \mathrm{n}^{\circ} 406240-126120$. SG and VM thank the Ceramics Laboratory, the Laboratory of Mechanical Metallurgy and the Interdisciplinary Center for Electron Microscopy at the Ecole Polytechnique Fédérale de Lausanne, Switzerland, for the use of the XRD, furnace and SEM, respectively. They also would like to thank Dr. D. Mari from EPFL for advice on the physics of damping. NJK and PM acknowledge financial support from the National Science Foundation (NSF) through project DMR-1207192.

\section{References}

[1] Ullakko K, Huang JK, Kantner C, O'Handley RC, Kokorin VV. Large magnetic-fieldinduced strains in $\mathrm{Ni}_{2} \mathrm{MnGa}$ single crystals. Appl Phys Lett. 1996;69(13):1966-8.

[2] Sozinov A, Likhachev AA, Lanska N, Ullakko K. Giant magnetic-field-induced strain in NiMnGa seven-layered martensitic phase. Appl Phys Lett. 2002;80(10):1746-8.

[3] Marioni MA, O'Handley RC, Allen SM. Pulsed magnetic field-induced actuation of NiMn-Ga single crystals. Appl Phys Lett. 2003;83(19):3966-8.

[4] Sozinov A, Likhachev AA, Ullakko K. Magnetic and magnetomechanical properties of $\mathrm{Ni}-\mathrm{Mn}-\mathrm{Ga}$ alloys with easy axis and easy plane of magnetization. Proc SPIE. 2001;4333:189-96.

[5] Dunand DC, Müllner P. Size Effects on Magnetic Actuation in Ni-Mn-Ga ShapeMemory Alloys. Adv Mater. 2011;23(2):216-32.

[6] Scheerbaum N, Heczko O, Liu J, Hinz D, Schultz L, Gutfleisch O. Magnetic fieldinduced twin boundary motion in polycrystalline Ni-Mn-Ga fibres. New J Phys. 2008;10(7):073002. 
[7] Chmielus M, Zhang XX, Witherspoon C, Dunand DC, Müllner P. Giant magnetic-fieldinduced strains in polycrystalline Ni-Mn-Ga foams. Nature Materials. 2009;8(11):863-6.

[8] Scheerbaum N, Hinz D, Gutfleisch O, Muller KH, Schultz L. Textured polymer bonded composites with Ni-Mn-Ga magnetic shape memory particles. Acta Mater. 2007;55(8):2707-13.

[9] Feuchtwanger J, Michael S, Juang J, Bono D, O'Handley RC, Allen SM, Jenkins C, Goldie J, Berkowitz A. Energy absorption in Ni-Mn-Ga-polymer composites. J Appl Phys. 2003;93(10):8528-30.

[10] Sun XG, Xie CY. Damping characteristics of a NiMnGa/polymer composite material. Mater Sci Forum. 2007;561-565:697-9.

[11] Feuchtwanger J, Lazpita P, Vidal N, Barandiaran JM, Gutierrez J, Hansen T, Peel M, Mondelli C, O'Handley RC, Allen SM. Rearrangement of twin variants in ferromagnetic shape memory alloy-polyurethane composites studied by stroboscopic neutron diffraction. J Phys-Condes Matter. 2008;20(10):104247.

[12] Lahelin M, Aaltio I, Heczko O, Soderberg O, Ge Y, Lofgren B, Hannula SP, Seppala J. DMA testing of Ni-Mn-Ga/polymer composites. Compos Pt A-Appl Sci Manuf. 2009;40(2):125-9.

[13] Sozinov A, Likhachev AA, Ullakko K. Crystal structures and magnetic anisotropy properties of Ni-Mn-Ga martensitic phases with giant magnetic-field-induced strain. IEEE Trans Magn. 2002;38(5):2814-6.

[14] Straka L, Hänninen H, Soroka A, Sozinov A. Ni-Mn-Ga single crystals with very low twinning stress. J Phys: Conf Series. 2011;303(1):012079.

[15] Straka L, Lanska N, Ullakko K, Sozinov A. Twin microstructure dependent mechanical response in Ni-Mn-Ga single crystals. Appl Phys Lett. 2010;96(13):131903.

[16] Qian MF, Zhang XX, Witherspoon C, Sun JF, Müllner P. Superelasticity and shape memory effects in polycrystalline $\mathrm{Ni}-\mathrm{Mn}-\mathrm{Ga}$ microwires. J Alloy Compdl. 10.1016/j.jallcom.2011.10.117 (in press).

[17] Jiang C, Muhammad Y, Deng L, Wu W, Xu H. Composition dependence on the martensitic structures of the Mn-rich NiMnGa alloys. Acta Mater. 2004;52(9):2779-85.

[18] Heczko O, Svec P, Janickovic D, Ullakko K. Magnetic properties of Ni-Mn-Ga ribbon prepared by rapid solidification. IEEE Trans Magn. 2002;38(5):2841-3.

[19] Lanska N, Soderberg O, Sozinov A, Ge Y, Ullakko K, Lindroos VK. Composition and temperature dependence of the crystal structure of Ni-Mn-Ga alloys. J Appl Phys. 2004;95(12):8074-8. 
[20] Richard M, Feuchtwanger J, Schlagel D, Lograsso T, Allen SM, O'Handley RC. Crystal structure and transformation behavior of Ni-Mn-Ga martensites. Scripta Materialia. 2006;54(10):1797-801.

[21] Pons J, Chernenko VA, Santamarta R, Cesari E. Crystal structure of martensitic phases in Ni-Mn-Ga shape memory alloys. Acta Mater. 2000;48(12):3027-38.

[22] Waitz T, Mangler C, Kompatscher A, Müllner P. Microscopy Conference 2013: Symposium on Functional Materials. Regensburg, Germany, August, 2013.

[23] Segui C, Cesari E, Pons J. Intermartensitic transformations in Ni-Mn-Ga alloys: A general view. Advanced Materials Research. 2008;52:47-55.

[24] Likhachev AA, Sozinov A, Ullakko K. Different modeling concepts of magnetic shape memory and their comparison with some experimental results obtained in Ni-Mn-Ga. Mater Sci Eng A-Struct Mater Prop Microstruct Process. 2004;378(1-2):513-8.

[25] Weibull W. A statistical theory for the strength of materials. Ingenjörsvetenskapsakademiens Handlingar. 1939;151:1-45.

[26] Glock S, Spārniņš E, Leterrier Y, Michaud V. Effect of annealing and silylation on the strength of melt-spun Ni-Mn-Ga fibres and their adhesion to epoxy. Submitted to: International journal of adhesion and adhesives. 2014.

[27] Montserrat S. Physical aging studies in epoxy resins. I. Kinetics of the enthalpy relaxation process in a fully cured epoxy resin. Journal of Polymer Science Part B: Polymer Physics. 1994;32(3):509-22.

[28] Chandra R, Singh S, Gupta K. Damping studies in fiber-reinforced composites-a review. Compos Struct. 1999;46(1):41-51.

[29] Feuchtwanger J, Richard ML, Tang YJ, Berkowitz AE, O'Handley RC, Allen SM. Large energy absorption in Ni-Mn-Ga/polymer composites. J Appl Phys. 2005;97(10):10M319.

[30] Zhu J-S, Schaller R, Benoit W. Internal friction transitory effects associated with martensitic transformation in Ni-Ti alloys. physica status solidi (a). 1988;108(2):613-8. 


\section{Table 1}

Composition of the as-spun and annealed melt-spun Ni-Mn-Ga wires measured on the wire surface and fractured cross section, respectively.

\begin{tabular}{llllllll}
\hline Position & State & $\begin{array}{l}\mathrm{Ni} \\
(\mathrm{at} \%)\end{array}$ & $\begin{array}{l}\Delta \mathrm{Ni} \\
(\mathrm{at} \%)\end{array}$ & $\begin{array}{l}\mathrm{Mn} \\
(\mathrm{at} \%)\end{array}$ & $\begin{array}{l}\Delta \mathrm{Mn} \\
(\mathrm{at} \%)\end{array}$ & $\begin{array}{l}\mathrm{Ga} \\
(\mathrm{at} \%)\end{array}$ & $\begin{array}{l}\Delta \mathrm{Ga} \\
(\mathrm{at} \%)\end{array}$ \\
\hline Surface & As-spun & 49.3 & 0.1 & 28.6 & 0.1 & 22.1 & 0.1 \\
& Annealed & 49.2 & 0.2 & 28.6 & 0.1 & 22.2 & 0.2 \\
\multirow{3}{*}{ Cross section } & As-spun & 49.4 & 0.2 & 30.0 & 1.6 & 20.6 & 1.6 \\
& Annealed & 49.7 & 0.5 & 29.3 & 1.5 & 21.0 & 2.0 \\
\hline
\end{tabular}

Table 2

Transformation temperatures. Annealing resulted in higher transformation temperatures.

\begin{tabular}{llllll}
\hline State & $A_{s}\left({ }^{\circ} \mathrm{C}\right)^{\mathrm{a}}$ & $A_{f}\left({ }^{\circ} \mathrm{C}\right)^{\mathrm{b}}$ & $M_{s}\left({ }^{\circ} \mathrm{C}\right)^{\mathrm{c}}$ & $M_{f}\left({ }^{\circ} \mathrm{C}\right)^{\mathrm{d}}$ & $T_{c}\left({ }^{\circ} \mathrm{C}\right)^{\mathrm{e}}$ \\
\hline As-spun & 82 & 95 & 86 & 70 & 93 \\
Annealed & 97 & 103 & 99 & 92 & 101 \\
\hline
\end{tabular}

${ }^{\mathrm{a}} A_{S}$ is the austenite start temperature.

${ }^{\mathrm{b}} A_{f}$ is the austenite finish temperature.

${ }^{\mathrm{c}} M_{s}$ is the martensite start temperature.

${ }^{\mathrm{d}} M_{f}$ is the martensite finish temperature.

${ }^{\mathrm{e}} T_{c}$ is the Curie temperature.

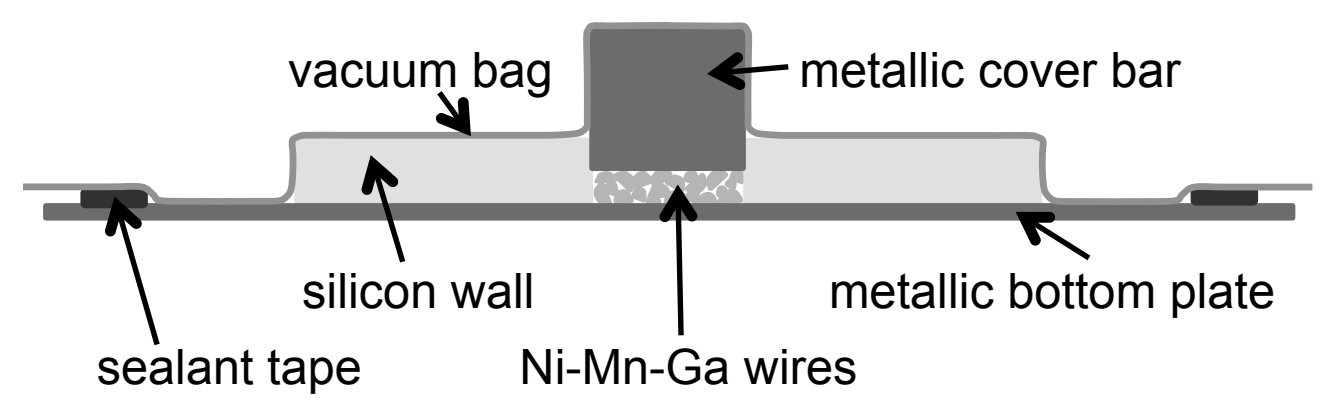

Fig. 1. Vacuum infusion set-up to produce Ni-Mn-Ga-wire epoxy-matrix composite samples for damping tests. The resin is infused perpendicular to the plane shown here. 

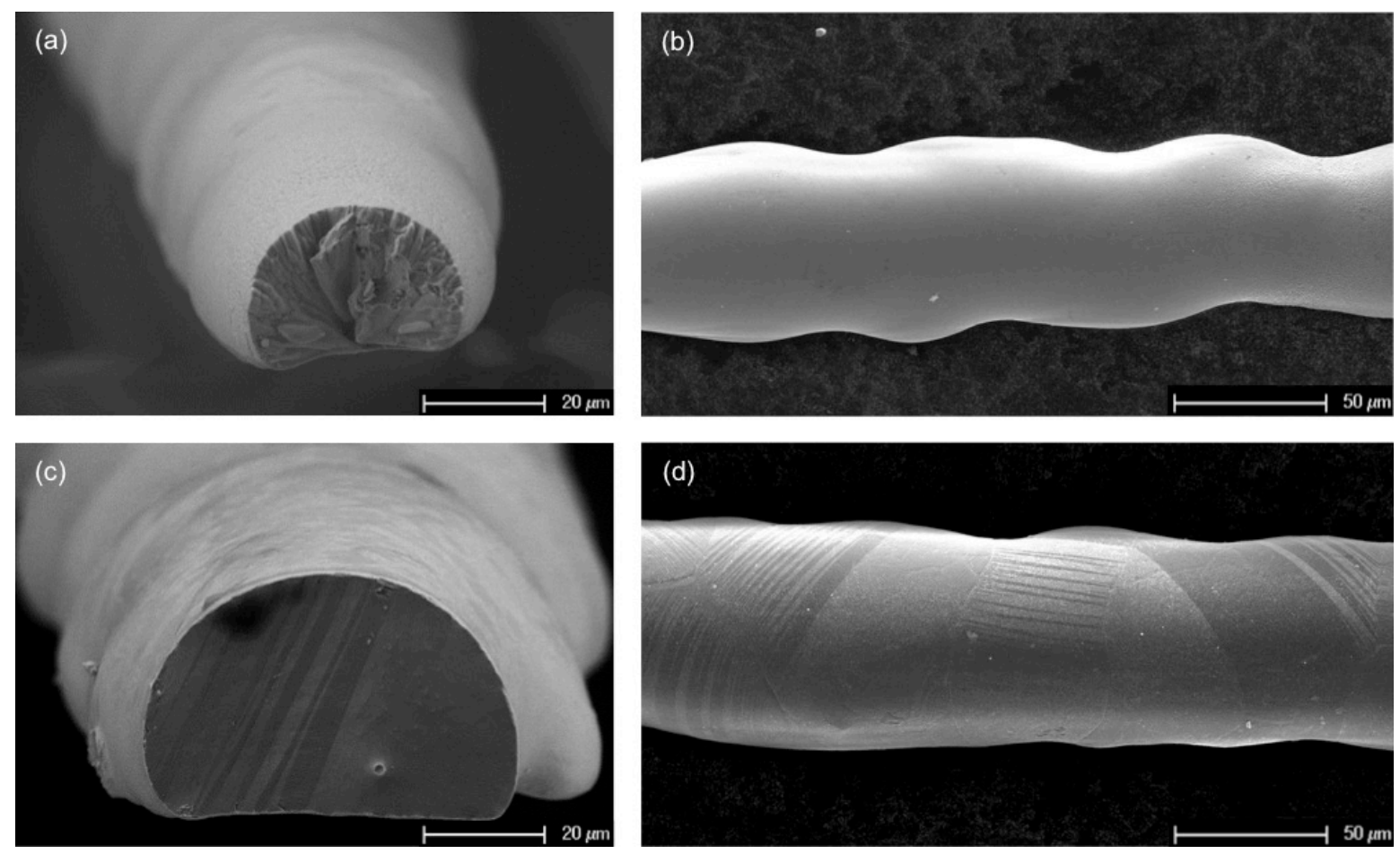

Fig. 2. SEM micrographs of cross section and surface of the as-spun (a, b) and the annealed (c, d) melt-spun Ni-Mn-Ga wires. The wires exhibited a semi-circular cross-section and an irregular diameter. The as-spun wires had dendritic like grains, the annealed wires exhibited a twinned bamboo- or near bamboo-structure.

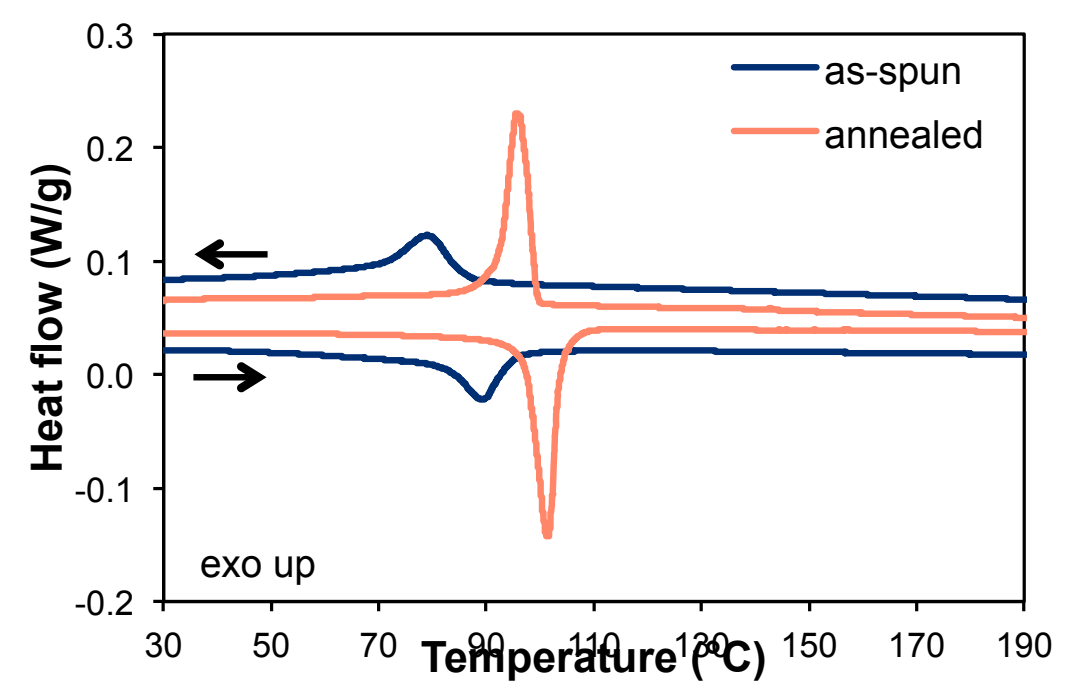

Fig. 3. DSC curves of the as-spun and annealed Ni-Mn-Ga wires. The martensitic/austenitic transformation peak is clearly visible. 


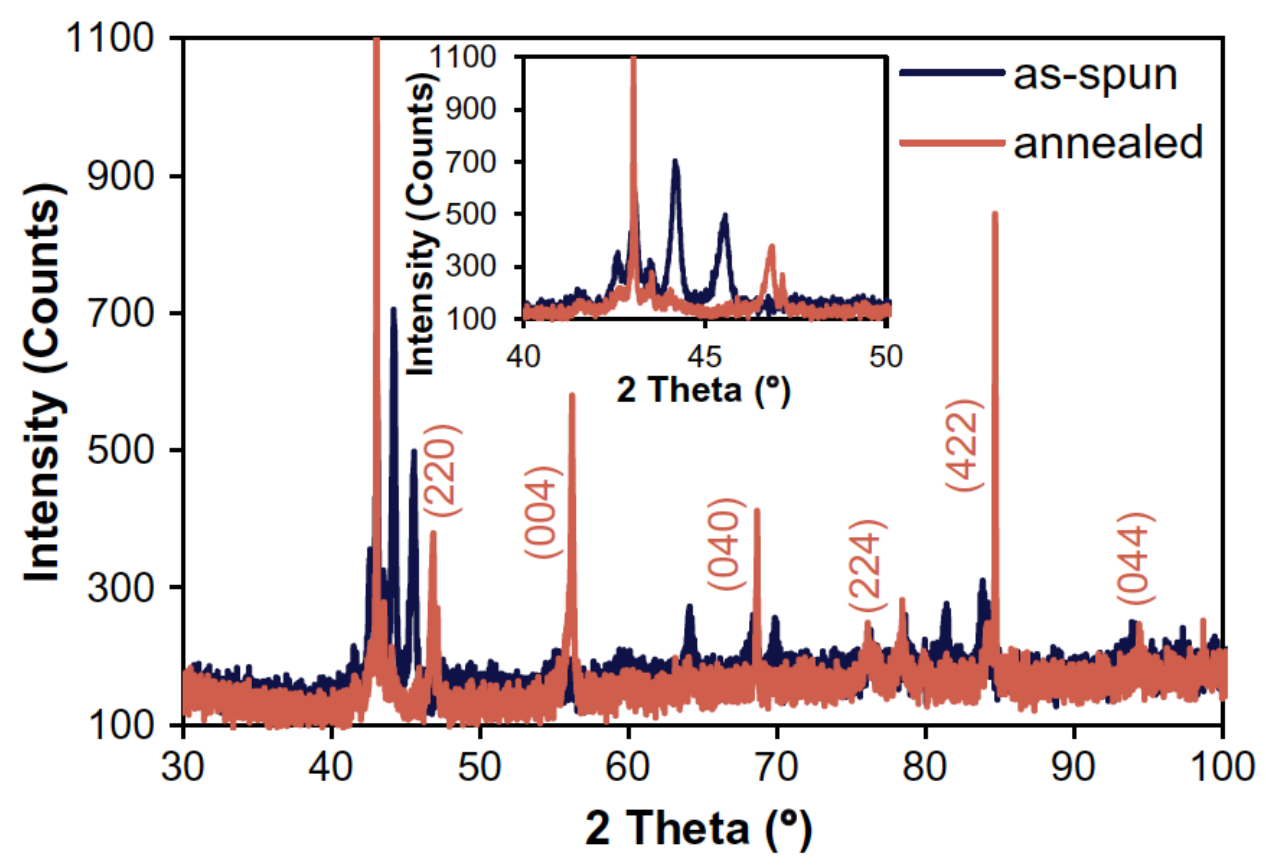

Fig. 4. XRD patterns of the as-spun and annealed wires. The insertion shows the 2 theta range of $40^{\circ}$ to $50^{\circ}$ enlarged. While the as-spun wires exhibited a $14 \mathrm{M}$ martensite structure the crystal structure of the annealed wires was NM.

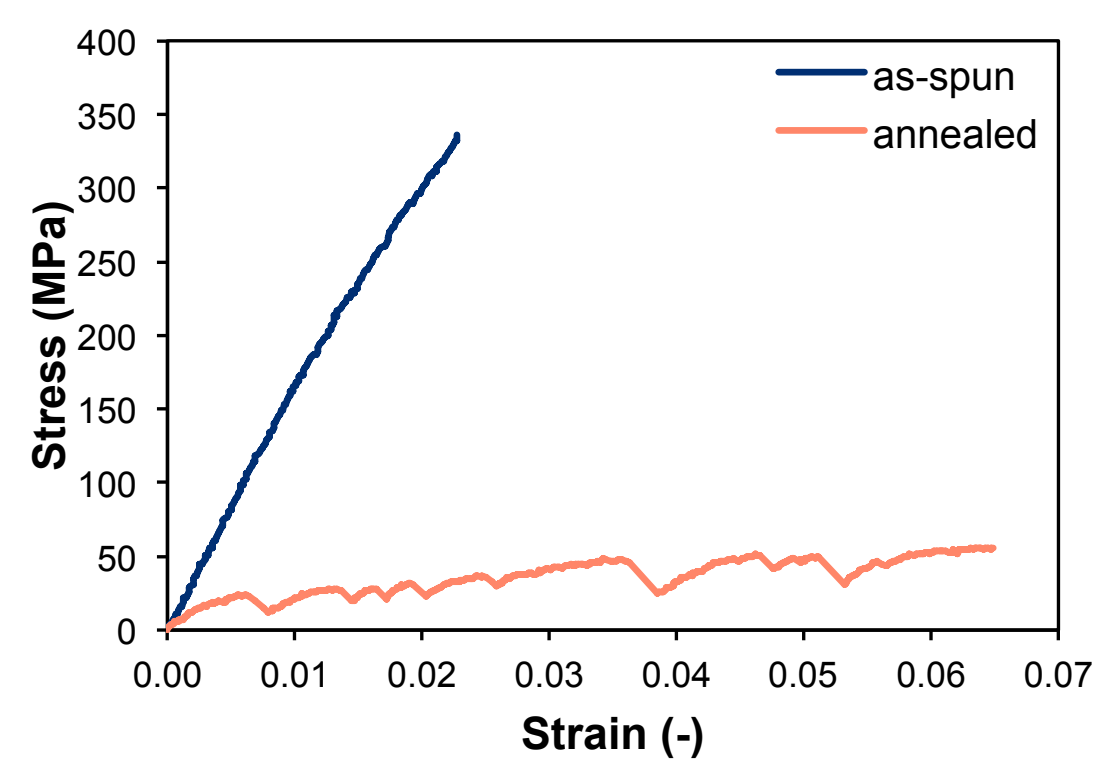

Fig. 5. Typical stress-strain curves of an as-spun and an annealed melt-spun Ni-Mn-Ga wire. While the as-spun wire failed brittle with almost no plastic deformation the annealed wire deformed to $6.5 \%$ with pronounced stress serrations. 

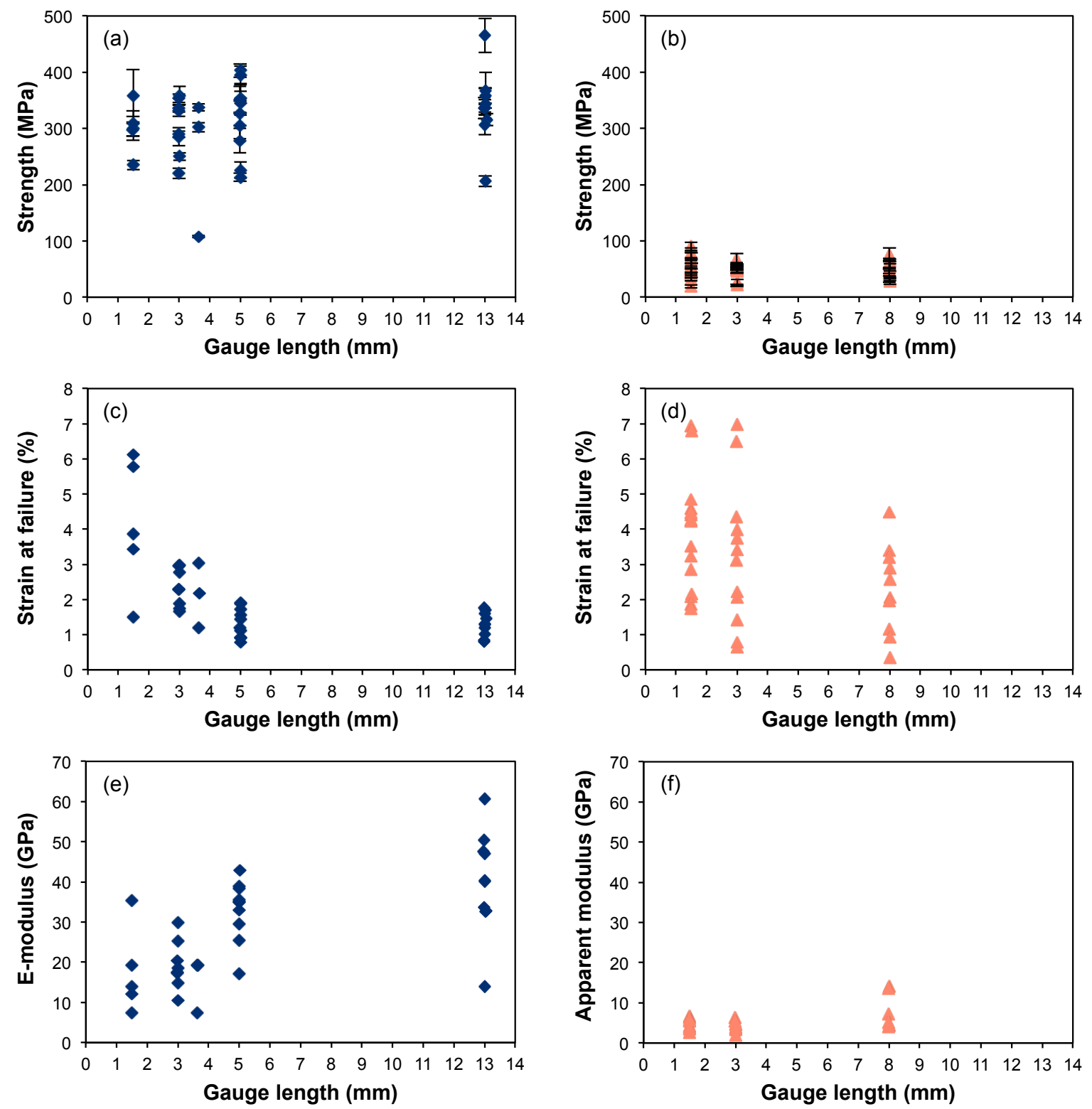

Fig. 6. Strength (a, b), strain to failure (c, d) and E-modulus (e, f) of the as-spun (a, c, e) and the annealed (b, d, f) Ni-Mn-Ga wires for different gauge lengths. Strength and E-modulus were higher for the as-dawn wires whereas the strain at failure was higher for the annealed wires. A dependency of the strength on the gauge length could not be proved in the measurement range for both types of wire. 

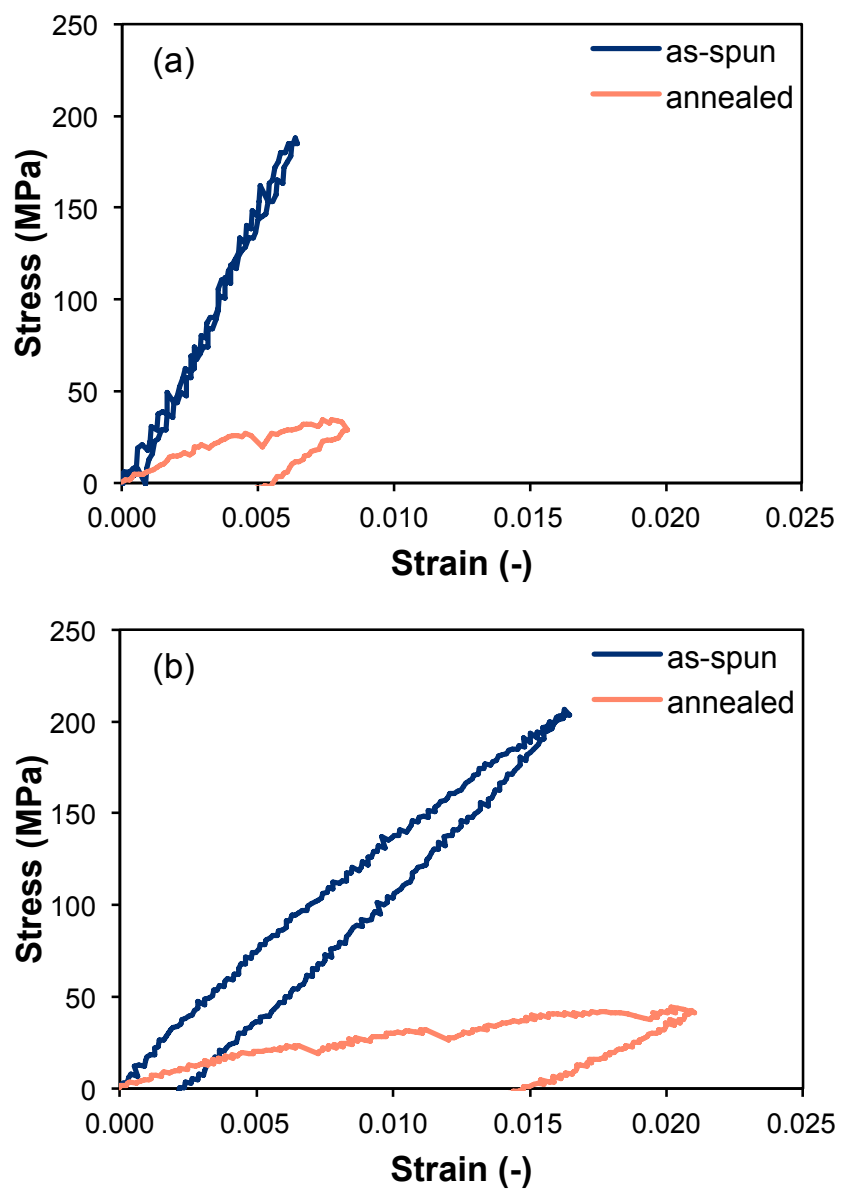

Fig. 7. Cyclic stress-strain curves of as-spun and annealed Ni-Mn-Ga wires for a maximum strain within the linear-elastic range of the as-spun wire (a) and a maximum strain close to the strain at failure of the as-spun wire (b). Slight plastic deformation was observed in as-spun wires loaded close to failure. 


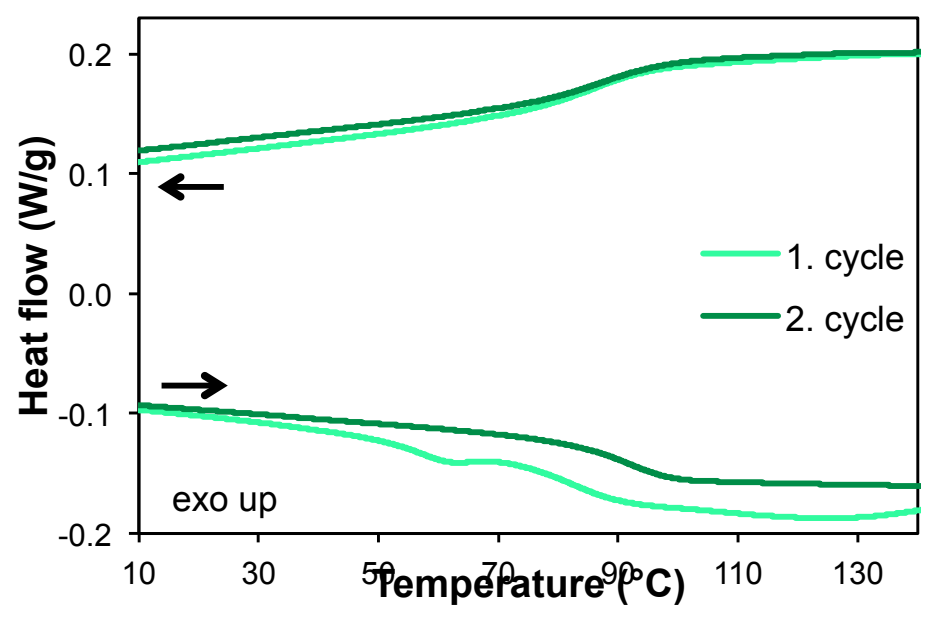

Fig. 8. DSC curves of the cured epoxy system Araldite LY 3297/Aradur 3298.
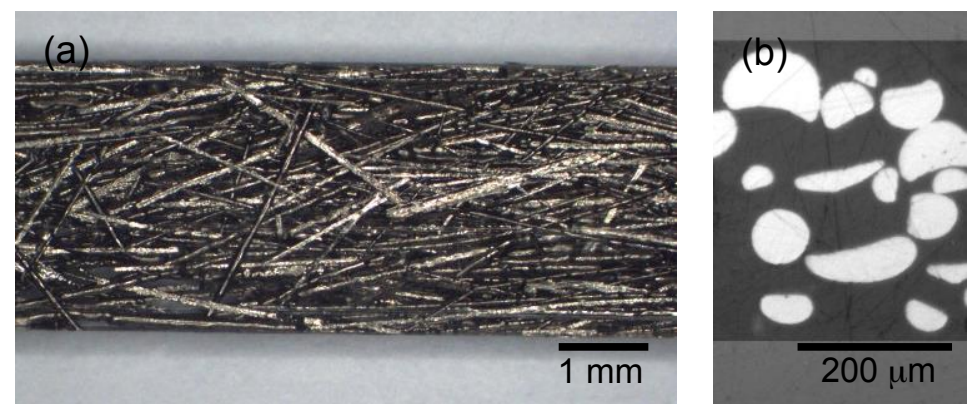

Fig. 9. Micrographes of the surface (a) and cross section (b) of a Ni-Mn-Ga wire-epoxy matrix composite.

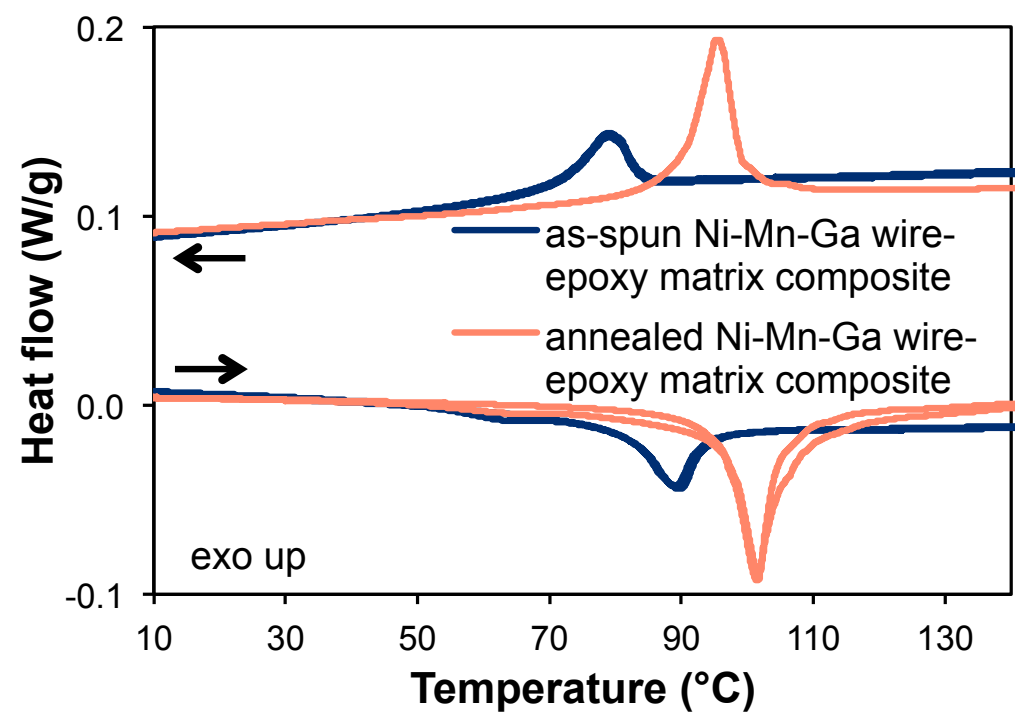

Fig. 10. DSC curves of an as-spun and an annealed Ni-Mn-Ga wire-epoxy matrix composite. 


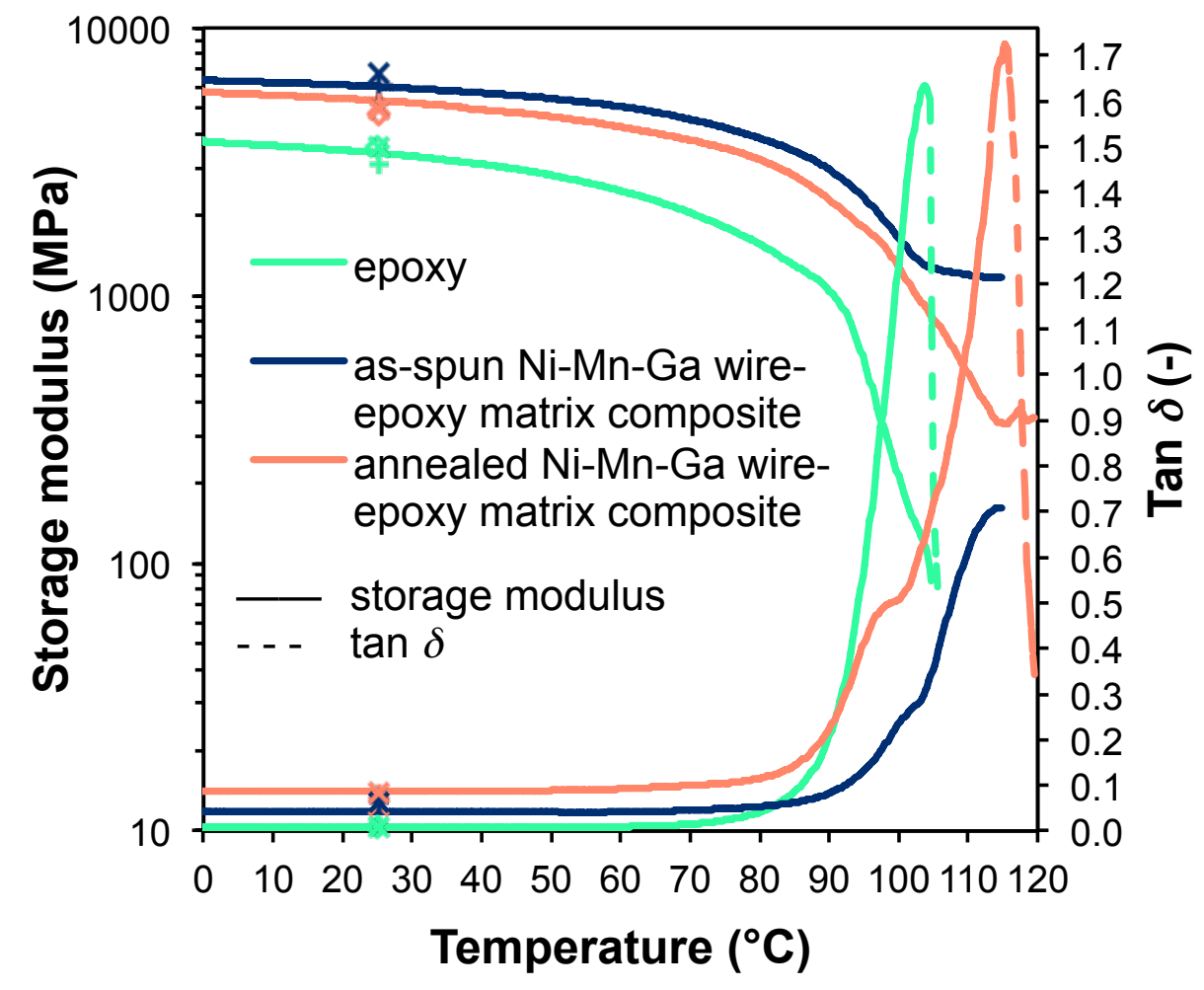

Fig. 11. Storage modulus and loss ratio $(\tan \delta)$ as a function of temperature for a pure epoxy sample, an as-spun Ni-Mn-Ga wire-epoxy matrix composite and an annealed Ni-Mn-Ga wire-epoxy matrix composite as well as data scatter for the different samples of the same type at room temperature. 